\title{
Alteration of RhoA Prenylation Ameliorates Cardiac and Vascular Remodeling in Spontaneously Hypertensive Rats
}

\author{
Jian Yang ${ }^{a} \quad$ Yu-Ning Chen ${ }^{b} \quad$ Zao-Xian Xua $\quad$ Yun Mou ${ }^{c} \quad$ Liang-Rong Zheng ${ }^{a}$ \\ aDepartment of Cardiology, The First Affiliated Hospital, College of Medicine, Zhejiang University, \\ Hangzhou, bepartment of Cardiology, Zhejiang Greentown Cardiovascular Hospital, Hangzhou, \\ 'Department of Ultrasound, The First Affiliated Hospital, College of Medicine, Zhejiang University, \\ Hangzhou, China
}

\section{Key Words}

Farnesyl pyrophosphate synthase $\cdot$ Cardiovascular remodeling $\cdot$ Geranylgeranylation of RhoA - Spontaneously hypertensive rats

\begin{abstract}
Background: In our previous study, farnesyl pyrophosphate synthase (FPPS) was shown to be increased in spontaneously hypertensive rats (SHR) and in mice with angiotensin-II induced cardiac hypertrophy. Overexpression of FPPS induced cardiac hypertrophy and fibrosis in mice, accompanied by an increase in the synthesis of farnesyl pyrophosphate (FPP) and geranylgeranyl pyrophosphate (GGPP). In the present study, we investigated the mechanisms of reversing cardiovascular remodeling in SHR by inhibiting FPPS. Methods and Results: Six-week-old rats were given vehicle or an FPPS inhibitor (alendronate, $100 \mathrm{ug} / \mathrm{kg} / \mathrm{d}$ ) daily for twelve weeks by osmotic mini-pump. The results demonstrated that FPPS inhibition attenuated cardiac hypertrophy and fibrosis in SHR as shown by the heart weight to body weight ratio, echocardiographic parameters, and histological examination. In addition, FPPS inhibition attenuated aortic remodeling as shown by reduced media thickness, media crosssectional area and collagen of the aorta as well as SBP, DBP, MBP. Furthermore, 12 weeks of alendronate treatment significantly decreased FPP and GGPP levels, RhoA activation and geranylgeranylation in the heart and aorta, all of which were significantly upregulated in SHR compared with normotensive Wistar-Kyoto rats. Conclusion: Taken together, these results indicate that chronic treatment with alendronate decreases the development of cardiac and aortic remodeling, by a pathway which involves inhibition of the geranylgeranylation and activation of RhoA.
\end{abstract}




\begin{tabular}{|c|c|c|}
\hline \multirow{2}{*}{$\begin{array}{l}\text { Cellular Physiology } \\
\text { and Biochemistry }\end{array}$} & \multicolumn{2}{|c|}{ Cell Physiol Biochem 2016;39:229-241 } \\
\hline & $\begin{array}{l}\text { DOI: } 10.1159 / 000445619 \\
\text { Published online: June 24, } 2016\end{array}$ & $\begin{array}{l}\text { O } 2016 \text { The Author(s). Published by S. Karger AG, Basel } \\
\text { www.kargercom/cpb }\end{array}$ \\
\hline
\end{tabular}

\section{Introduction}

Cardiac remodeling, including cardiac fibrosis and hypertrophy, contribute to high morbidity and mortality in many heart diseases. It is known that cardiomyocytes undergo remodeling in response to some pathological stimuli, including neurohumoral factors, pressure or volume overload, biomechanical stress, myocarditis, or inherited mutations [1-3]. However, the compensatory response is limited, and as the stimuli persists, the cardiac remodeling become maladaptive and eventually causes heart failure [4-7]. Vascular remodeling is defined as any enduring change in the size and/or composition of an adult blood vessel following adaptation and repair. Hypertensive vascular remodeling underlies the pathogenesis of major cardiovascular diseases, such as atherosclerosis and restenosis. However, further molecular functions involved in cardiac and vascular remodeling need to be determined.

It is known that the small GTPases-Ras and Rho-regulate many aspects of cytoskeletal function, including cardiovascular remodeling. Cardiac overexpression of RhoA leads to the development of congestive heart failure with bradycardia and the induction of interstitial fibrosis [8]. Cardiac-specific RhoA-deficient mice showed accelerated heart failure, but not cardiac fibrosis in response to pressure-overload [9], and overexpression of Rac1 led to a lethal dilated cardiomyopathy [10]. Cardiac targeted V12H-Ras transgenic mice displayed cardiac hypertrophy and selective diastolic dysfunction [11]. All of these G proteins require post-translational modification for their membrane localization and biological function, such as lipidation [12]. One type of protein lipidation, isoprenylation, is necessary for the translocation of an inactive GTPase from the cytosol to the membrane and triggers a downstream cell signaling pathway [13].

Protein prenylation includes geranylgeranylation (modification with GGPP by geranylgeranyltransferase type I (GGTase-I) and farnesylation (modification with FPP by farnesyltransferase (FTase)), both of which are biosynthesized from acetyl-CoA through the mevalonate pathway (MVP, Fig. 1A) [14]. Farnesyl pyrophosphate synthase (FPPS) is a key enzyme in the MVP pathway and directly catalyzes the synthesis of FPP and GGPP, which are required for isoprenylation of small GTPases. Therefore, we reasoned that FPPS is critical for protein prenylation, which modulates cardiac hypertrophy and fibrosis in spontaneously hypertensive rats (SHR); however, direct evidence in support of this hypothesis is insufficient.

In our previous study, we showed that FPPS was upregulated in SHR, and chronic inhibition of FPPS could attenuate cardiac remodeling in SHR [15]. Cardiac-specific overexpression of FPPS in mice induced cardiac hypertrophy and dysfunction through increased synthesis of FPP and GGPP [16]. We also demonstrated that inhibition of FPPS attenuates Ang-II induced cardiac hypertrophy and fibrosis, accompanied by a decrease in FPP and GGPP levels [17]. Therefore, these studies showed that FPPS may modulate cardiac fibrosis and hypertrophy. However, the complicated mechanism of FPPS in cardiovascular remodeling is unclear and protein prenylation in SHR is unknown. In the present study, we investigated the mechanism of cardiac and vascular remodeling in SHR following inhibition of FPPS.

\section{Materials and Methods}

Animals and reagents

Six-week-old male SHR and normotensive Wistar-Kyoto (WKY) rats were purchased from the Shanghai Laboratory Animal Center, Chinese Academy of Sciences, and housed in a pathogen-free laboratory in Zhejiang University. The investigation conformed to the Guide for the Care and Use of Laboratory Animals published by the US National Institutes of Health (NIH Publication, 8th Edition, 2011) and the guidelines of the Animal Care and Use Committee of Zhejiang University.

Twelve male SHR were randomly divided into two groups consisting of the saline group (SHR) and alendronate group (SHA). Six male age- and weight-matched WKY rats were housed as controls (WKY).

\section{KARGER}




\section{Cellular Physiology Cell Physiol Biochem 2016;39:229-241 and Biochemistry Published online: June 24, $2016 \quad$\begin{tabular}{l|l} 
DOI: 10.1159/000445619 & $\begin{array}{l}\text { (c) } 2016 \text { The Author(s). Published by S. Karger AG, Basel } \\
\text { www.karger.com/cpb }\end{array}$
\end{tabular} \\ Yang et al: FPPS Inhibition and Cardiovascular Remodeling}

Saline and alendronate $(0.1 \mathrm{mg} / \mathrm{kg} /$ day) were administered for 4 weeks via an osmotic mini-pump (Alzet model 2004, Durect Corp., Cupertino, CA, USA), which were subcutaneously implanted between the scapulae in rats following anesthesia with sodium pentobarbital (Sigma, St. Louis, MO, USA, $40 \mathrm{mg} / \mathrm{kg}$, i.p.). The adequacy of anaesthesia was monitored by the lack of the pedal withdrawal reflex, slow constant breathing, and no response to surgical manipulation. The osmotic mini-pump was changed every 4 weeks for 12 weeks, and the dose of alendronate $(0.1 \mathrm{mg} / \mathrm{kg} /$ day $)$ was chosen according to the results of previous studies $[18,19]$.

FPP, GGPP, n-octyl-b-glucopyranoside, and alendronate were purchased from Sigma. D*- GCVLS and D*-GCVLL (dansyl-labeled peptides) were obtained from EMD Biosciences (La Jolla, CA, USA) and CPC (Hangzhou, China). Rat recombinant FTase and GGTase-I were purchased from EMD Biosciences. A Bond ProElut C18 solid phase extraction (SPE) column $(200 \mathrm{mg}, 3 \mathrm{ml})$ was purchased from Dikma Technologies Inc. (Beijing, China).

\section{Two-dimensional echocardiography}

Rats were lightly anesthetized with an intraperitoneal injection of sodium pentobarbital (Sigma, $40 \mathrm{mg} / \mathrm{kg}$ ) and transthoracic two-dimensional and M-mode images were acquired using a Sonos 5500 Echocardiographic 95 System (Philips Medical Systems, Andover, MA, USA) equipped with a $14 \mathrm{MHz}$ transducer. The M-mode recordings were made from digital images by using the analysis software (Sonos 5500 software package). M-mode images were used to measure the thickness of interventricular septum wall (IVSd) and posterior wall (LVPWT) at diastolic phase. The Ejection Fractions (EF) was calculated according to measurements of the left ventricular (LV) end diastolic and end systolic diameters by the echocardiographic system.

\section{Blood pressure}

Systolic blood pressure (SBP), diastolic blood pressure (DBP) and mean blood pressure (MBP) were measured while the rats were conscious using a Tail-cuff Pressure Analysis System (BP-98A; Softron, Tokyo, Japan). Briefly, the rats were incubated in a chamber at $35^{\circ} \mathrm{C}$ for $10 \mathrm{~min}$, and then placed in plastic restrainers. A cuff with a pneumatic pulse sensor was attached to the tail. Data were averaged for 6-7 cycles.

Lipid measurements

A 5-ml blood sample was collected from each rat, the serum was isolated, and the levels of total cholesterol (TC), high-density lipoprotein cholesterol (HDL-C), and low-density lipoprotein cholesterol (LDL-C) were measured with commercially enzymatic kits.

\section{Histological analysis}

The weight of the heart (HW) was measured, the ratio of HW to body weight (HW/BW) and HW to tibia length (HW/TL) were calculated as an index of cardiac hypertrophy. Sections of ventricle were fixed in 10\% neutral formalin, embedded in paraffin, and stained with hematoxylin and eosin (HE) for cardiomyocytes or sirius red for microscopy to show the area of interstitial or perivascular fibrosis. In addition, three $5-\mu \mathrm{m}-$ thick sections of thoracic aorta from each rat were cut and stained with HE to determine media thickness (MT) and media cross-sectional area (MCSA).

\section{Assessment of RhoA and Ras activation}

Heart tissue protein was isolated by homogenizing the tissue with cell lysis buffer. RhoA activity was determined using an absorbance-based G-LISA RhoA activation assay biochemistry kit (Kit \#BK124, Cytoskeleton) according to the manufacturer's instructions. This assay used a Rho-GTP-binding protein in the wells of a 96-well plate. Active GTP-bound RhoA bound to the wells, while inactive GDP-bound RhoA in cell lysates was removed during the washing steps. Bound GTP RhoA was detected by incubation with a RhoA specific antibody followed by a secondary antibody conjugated to horseradish peroxidase (HRP). The signal was read by measuring absorbance at $490 \mathrm{~nm}$ using a microplate reader (BIO RAD, Model 680).

The ELISA kit contained a Raf-RBD protein that was fused to GST in a 96-well plate coated with glutathione. GST-Raf-RBD was incubated in the wells for $1 \mathrm{~h}$ to immobilize the captured probe. Cell and hearttissue protein was added to the wells and incubated for $1 \mathrm{~h}$. A primary antibody to $\mathrm{H}$ - and $\mathrm{K}$-Ras was added to the wells and incubated for $1 \mathrm{~h}$. Wells were washed thrice and secondary antibody conjugated with HRP 


\section{Cellular Physiology Cell Physiol Biochem 2016;39:229-241 and Biochemistry Published online: June 24, $2016 \quad \begin{aligned} & \text { DOI: 10.1159/000445619 } 2016 \text { The Author(s). Published by S. Karger AG, Basel } \\ & \text { www.karger.com/cpb }\end{aligned}$ \\ Yang et al: FPPS Inhibition and Cardiovascular Remodeling}

added to each well, incubated, and washed thrice. Finally, the product was detected with chemiluminescent (ECL) reagents. The plate was read on a Luminometer (Infinite M200 Pro, Tecan, Männedorf, Switzerland), which provided a sensitive and quantitative chemiluminescent readout of activated Ras.

Farnesylated Ras and geranylgeranylated RhoA were evaluated by the Triton X-114 partition method as previously described [20]with minor modifications. In brief, the heart and aorta were homogenized in lysis buffer containing protease inhibitors and were centrifuged at 12,000 g. Equal volumes of lysate and $4 \%$ Triton X-114 were combined in a tube, vortexed, and incubated. The detergent phase of the solution was subjected to western blotting with anti-Pan Ras antibody (EMD Biosciences, San Diego, CA) and anti-RhoA antibody (Santa Cruz Biotechnology, Inc., CA).

\section{High-performance liquid chromatography assays of FPP and GGPP}

FPP and GGPP levels were quantified by high-performance liquid chromatography (HPLC)-fluorescence as previously described [21]. Briefly, heart and aorta tissues was homogenized with ice-cold extraction solvent (ethanol/0.5\% aqueous $\mathrm{NH} 4 \mathrm{OH}, 3: 1$ ). Tissue extracts were cleaned by passing them through the SPE column. The final eluted fractions were combined and dried under a stream of nitrogen gas at $60^{\circ} \mathrm{C}$. The residue was dissolved in $40 \mu \mathrm{l}$ of $50 \mathrm{mM}$ Tris- $\mathrm{HCl}$ assay buffer (pH 7.5) containing $5 \mathrm{mM}$ dithiothreitol (DTT), $5 \mathrm{mM} \mathrm{MgCl}, 10 \mu \mathrm{M} \mathrm{ZnCl}_{2}$, and 1.0\% octyl-b-d-glucopyranoside. Then $2.0 \mu \mathrm{l}$ of $\mathrm{D}^{*}$ GCVLS or D*-GCVLL $(125 \mu \mathrm{M})$ and $0.20 \mu \mathrm{l}$ of FTase $(1 \mathrm{mg} / \mathrm{ml}$ protein, $0.2 \mathrm{U})$ or $0.20 \mu \mathrm{l}$ of GGTase- $1(1 \mathrm{mg} /$ $\mathrm{ml}$ protein, $1.0 \mathrm{U}$ ) were added to the assay buffer. The assay mixture was incubated at $38^{\circ} \mathrm{C}$ for $2 \mathrm{~h}$, and the reaction was terminated by the addition of $50 \mu \mathrm{l}$ of acetonitrile and $5 \mu \mathrm{l}$ of $10 \% \mathrm{HCl}$. HPLC analysis was carried out using a Waters 600 system (600 pump, 474 scanning fluorescence detector) and a 717 autosampler (Waters Corp., Milford, MA, USA). The samples were separated using the Agilent Zorbax SBC18 column $(250 \mathrm{~mm} \times 4.6 \mathrm{~mm}$ I.D., $5 \mu \mathrm{m}$ ) (Agilent, Palo Alto, CA, USA). The retention times for FPP* and GGPP* were $4.9 \mathrm{~min}$ and $18.9 \mathrm{~min}$, respectively.

\section{Statistical analysis}

Results are expressed as mean \pm SEM. One-way analysis of variance (ANOVA) followed by the Bonferroni post hoc test were used to determine significant differences between different groups. Differences were considered statistically significant at a value of $\mathrm{P}<0.05$.

\section{Results}

Inhibition of FPPS reduced SBP, DBP and MBP in SHR

As expected, before treatment, the SBP, DBP and MBP in SHR were higher than those in WKY (164 $\pm 4.3 \mathrm{mmHg}$ vs. $123 \pm 2.8 \mathrm{mmHg}, \mathrm{P}<0.001 ; 105.7 \pm 3.2 \mathrm{mmHg}$ vs. $77.2 \pm 2.2$ $\mathrm{mmHg}, \mathrm{P}<0.001 ; 125.2 \pm 2.5 \mathrm{mmHg}$ vs. $92.3 \pm 1.9 \mathrm{mmHg}$, $\mathrm{P}<0.001$, respectively) (Fig. 1B). There were no significant differences between the SHR group and SHA group at baseline. Over the 12-week period, SBP, DBP and MBP increased further in the SHR group compared to the WKY group $(212 \pm 6.1 \mathrm{mmHg}$ vs. $121 \pm 4.3 \mathrm{mmHg}, \mathrm{P}<0.001 ; 161.2 \pm 5.0 \mathrm{mmHg}$ vs. $79 \pm 4.3 \mathrm{mmHg}, \mathrm{P}<0.001 ; 178.8 \pm 4.5 \mathrm{mmHg}$ vs. $93 \pm 2.9 \mathrm{mmHg}, \mathrm{P}<0.001$, respectively) Administration of alendronate for 12 weeks significantly reduced the SBP, DBP and MBP in the SHA group compared to the SHR group $(212 \pm 6.1 \mathrm{mmHg}$ vs. $191.8 \pm 5.1 \mathrm{mmHg}, \mathrm{P}<0.05$; $161.2 \pm 5.0 \mathrm{mmHg}$ vs. $140.8 \pm 4.6 \mathrm{mmHg}, \mathrm{P}<0.05 ; 178.8 \pm 4.5 \mathrm{mmHg}$ vs. $158 \pm 4.7 \mathrm{mmHg}, \mathrm{P}$ $<0.01$, respectively).

\section{Inhibition of FPPS decreased the lipid levels}

Serum TC, LDL, and HDL levels were significantly lower in SHR than in WKY rats. Administration of alendronate for 12 weeks markedly reduced the serum concentrations of TC and LDL in SHR, but did not influence the levels of HDL (Fig. 1C).

Inhibition of FPPS attenuates cardiac and vascular remodeling in SHR

At the end of treatment, SHR had a higher HW/BW ratio than the age-matched WKY rats. However, the HW/BW ratio was lower in the SHA group than in the SHR group (4.02 \pm 0.12 vs. $3.13 \pm 0.05, \mathrm{P}<0.001 ; 3.66 \pm 0.10$ vs. $4.02 \pm 0.12, \mathrm{P}<0.05$, respectively) (Fig. 


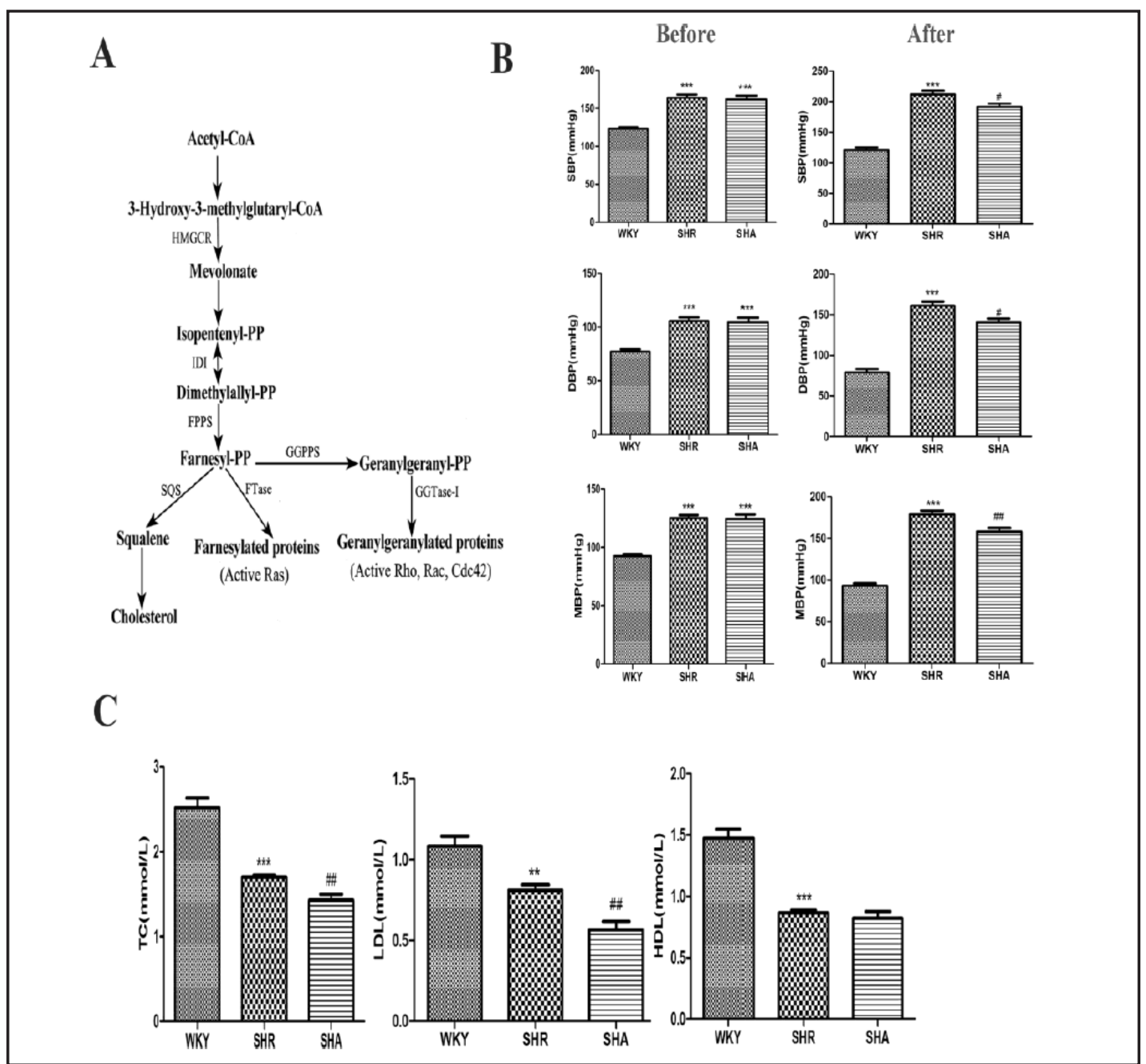

Fig. 1. (A) The mevalonate/isoprenoid/cholesterol pathway (abridged). FPP synthase (FPPS) catalyzes the synthesis of farnesylpyrophosphate (FPP) from mevalonate (MVA). FPP is a branching point and serves as a precursor of geranylgeranylpyrophosphate (GGPP) by the activity of GGPP synthase (GGPPS). FPP is also the precursor of cholesterol. (B) Effect of alendronate treatment on systolic blood pressure (SBP), dystolic blood pressure (DBP) and mean blood pressure (MBP). SBP, DBP and MBP were measured before study (before) and at the end of the study (After). These results are expressed as mean $\pm \mathrm{SEM}(\mathrm{n}=6) .{ }^{* * *} \mathrm{P}<0.001$ compared with WKY group, ${ }^{\#} \mathrm{P}<0.05$ and ${ }^{\# \# P}<0.01$ compared with SHR group. (C) Effects of alendronate on lipid profile in WKY and SHR at 18 weeks. These results are expressed as mean \pm SEM, $n=6$. HDL, high-density lipoprotein cholesterol; LDL, low-densitylipoprotein cholesterol; TC, total cholesterol. ${ }^{* *} \mathrm{P}<0.01$ and $^{* * *} \mathrm{P}<0.001$ compared with WKY group. ${ }^{\# \#} \mathrm{P}<0.01$ compared with SHR group.

2A). Similarly, SHR had a higher HW/TL ratio than the age-matched WKY rats, and the $\mathrm{HW} / \mathrm{TL}$ ratio was lower in the SHA group than in the SHR group $(42.4 \pm 1.10$ vs. $32.2 \pm$ $0.99, \mathrm{P}<0.001 ; 38.11 \pm 1.07$ vs. $42.4 \pm 1.10, \mathrm{P}<0.05$, respectively) (Fig. $2 \mathrm{~A}$ ). There were no significant differences in echocardiography data between the WKY, SHR and SHA groups at baseline. Over the 12-week period, interventricular septal thickness at diastole (IVSd) and left ventricular posterior wall thickness (LVPWT) increased in the SHR group compared to the WKY group $(0.23 \pm 0.01 \mathrm{~cm}$ vs. $0.17 \pm 0.01 \mathrm{~cm}, \mathrm{P}<0.001 ; 0.24 \pm 0.01 \mathrm{~cm}$ vs. $0.19 \pm 0.01$ $\mathrm{cm}, \mathrm{P}<0.01$, respectively), and alendronate administration significantly reduced the IVSd and LVPWT in the SHA group compared to the SHR group $(0.20 \pm 0.01 \mathrm{~cm}$ vs. $0.23 \pm 0.01$ $\mathrm{cm}, \mathrm{P}<0.05 ; 0.20 \pm 0.01 \mathrm{~cm}$ vs. $0.24 \pm 0.01 \mathrm{~cm}, \mathrm{P}<0.05$, respectively). However, the LV end- 
A

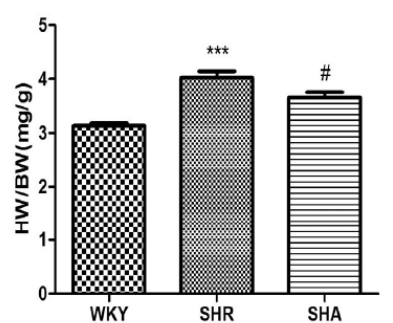

B

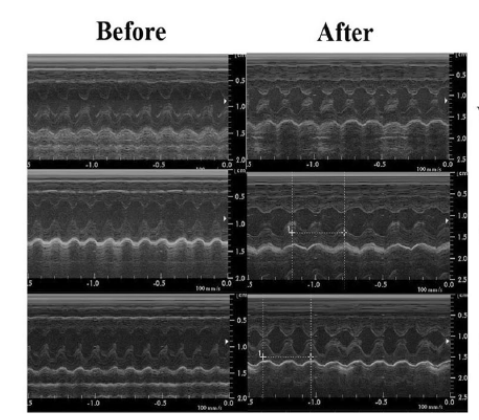

C

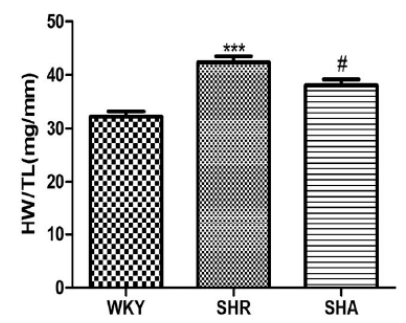

Before
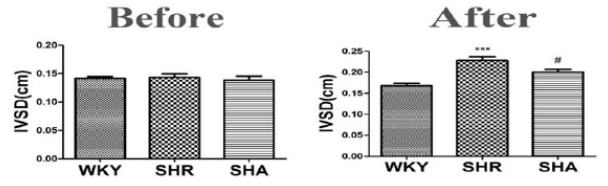

WKY
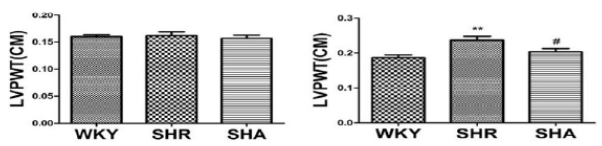

SHR
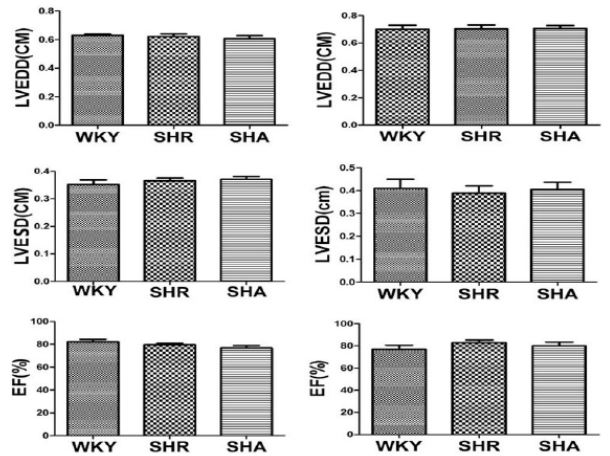

Fig. 2. (A) Effects of alendronate on cardiac hypertrophy index (HW/BW, HW/TL) in WKY and SHR at 18 weeks. These results are expressed as mean $\pm \mathrm{SEM}, \mathrm{n}=6 .{ }^{* * *} \mathrm{P}<0.001$ compared with WKY group. ${ }^{*} \mathrm{P}<0.05$ compared with SHR group. (B) Representative M-mode echocardiography in the rats before and after FPPS inhibition. (C) Effects of alendronate on echocardiography parameters in WKY and SHR before study (before) and at the end of the study (After). These results are expressed as mean $\pm \mathrm{SEM}, \mathrm{n}=6$. ${ }^{* *} \mathrm{P}<0.01$ and ${ }^{* * *} \mathrm{P}<0.001$ compared with WKY group." $\mathrm{P}<0.05$ compared with SHR group.

diastolic dimension (LVEDD), LV end-systolic dimension (LVESD), and ejection fraction (EF) did not differ in the SHR group and the SHA group (Fig. 2B,C).

Hematoxylin/eosin and sirius red stained histological sections in SHR exhibited a hypertrophic phenotype and cardiac fibrosis. As expected, the cross-sectional area of cardiomyocytes increased markedly in SHR compared with WKY and SHA rats (Fig. 3A). Using sirius red staining, we found that cardiac fibrosis significantly increased in SHR compared with WYK rats $(\mathrm{P}<0.001)$, and significantly decreased in the SHA group, as indicated by the red-stained area (Fig. 3B). Media thickness (MT) and media cross-sectional area (MCSA) of the thoracic aorta were both increased in SHR when compared with age-matched WKY rats, while alendronate treatment decreased the MT and MCSA in the SHA group (Fig. 4). Furthermore, using sirius red staining, we found that aortic collagen was increased in SHR compared with the WYK group, and decreased in the SHA group, as indicated by the redstained area (Fig. 4).

Inhibition of FPPS decreases FPP and GGPP levels in SHR

FPP and GGPP are critical for anchoring small G proteins to intracellular membranes, thus determining the localization and function of small $\mathrm{G}$ proteins. Therefore, it is important 
A

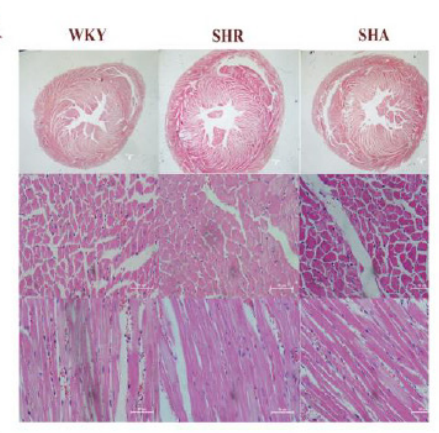

B

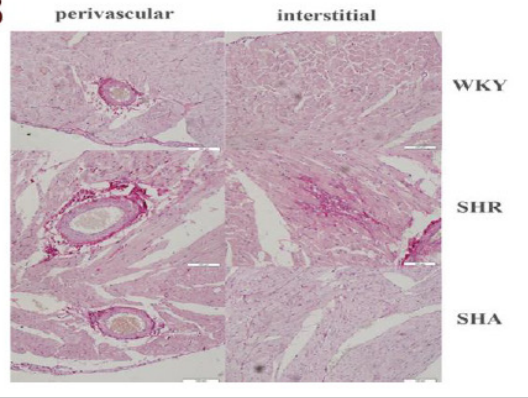

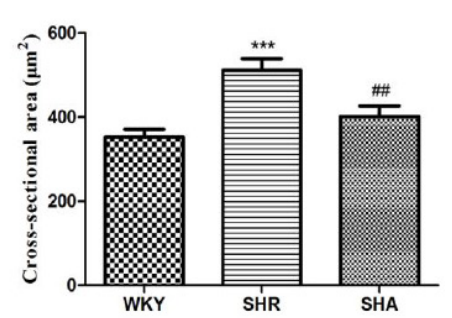
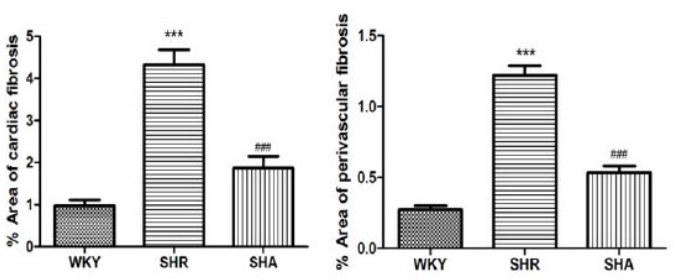

Fig. 3. Effects of alendronate on cardiac hypertrophy and fibrosis in WKY and SHR at 18 weeks (A) Left, representative hematoxylin/eosin (HE) and sirus red staining of the ventricles. Increased cardiomyocyte areas and interstitial, perivascular fibrosis (red) were obtained in SHR, while alendronate treatment attenuated this effect. Scale bar, $50 \mu \mathrm{m}$. Right, quantification of cardiomyocyte areas from HE stained cross-sections in rats ( $\mathrm{n}=3$ /group). ${ }^{* * *} \mathrm{p}<0.001 \mathrm{vs.} \mathrm{WKY,}{ }^{\# \#} \mathrm{p}<0.01$ vs. SHR. (B) Left, representative sirus red staining of the ventricles. Right, quantification of interstitial and perivascular fibrosis area from sirus red stained sections in rats ( $\mathrm{n}=3$ /group). ${ }^{* * *} \mathrm{p}<0.001$ vs. WKY, ${ }^{\# \# \#} \mathrm{p}<0.001$ vs. SHR.

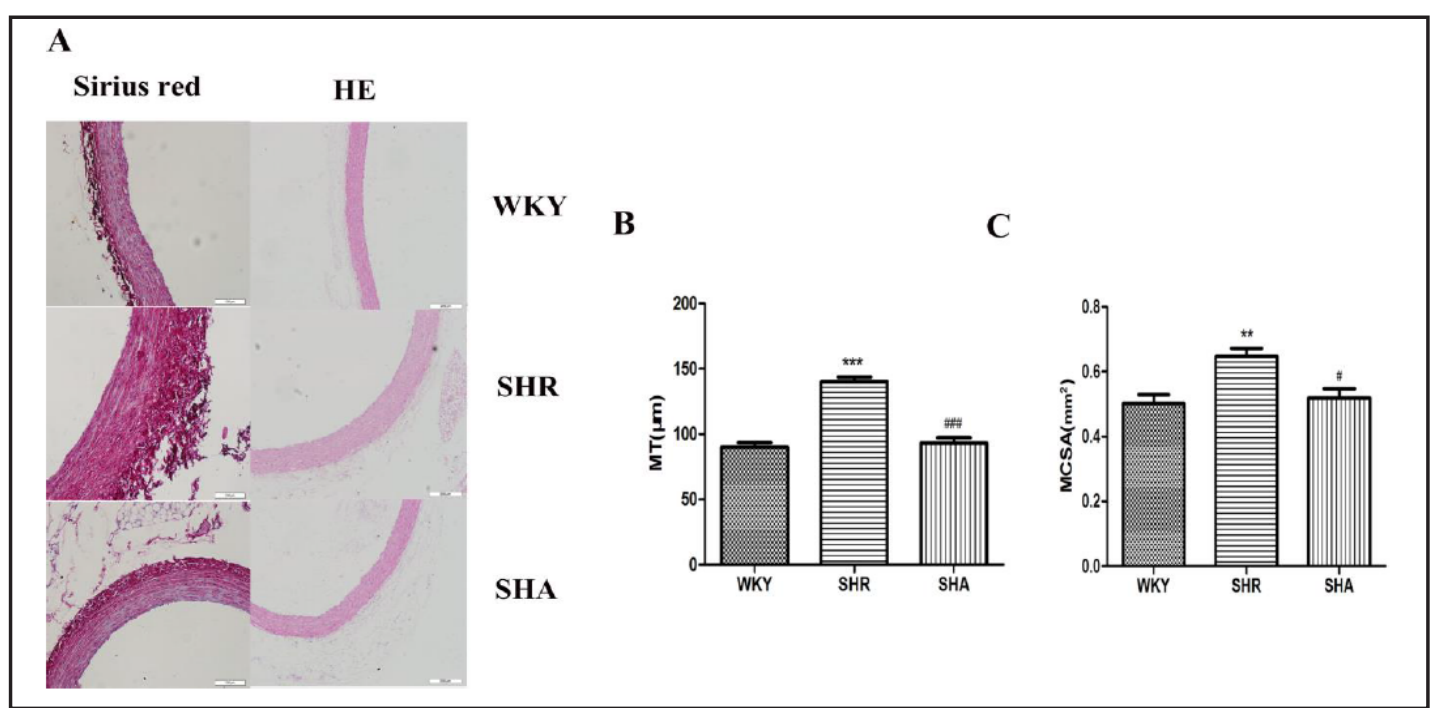

Fig. 4. Effects of alendronate on vascular remolding in WKY and SHR at 18 weeks (A) Left, representative sirus red staining of the aortas. Increased vascular collagen (red) were obtained in SHR, while alendronate treatment attenuated this effect. Scale bar, $100 \mu \mathrm{m}$. Right, representative HE stained of the aortas. Scale bar, $200 \mu \mathrm{m}$. (B) quantification of MT from HE stained cross-sections in rats ( $\mathrm{n}=3 /$ group). ${ }^{* * *} \mathrm{p}<0.001 \mathrm{vs.} \mathrm{WKY,}$ $\# \#$ p $<0.001$ vs. SHR. (C) quantification of MCSA in rats ( $n=3$ /group). ${ }^{* *} p<0.01$ vs. WKY, ${ }^{p} p<0.05$ vs. SHR.

to quantify FPP and GGPP levels in tissues. The results showed that (Fig. 5A,B), FPP and GGPP levels were significantly increased in the heart of SHR compared with WKY rats (75.4 \pm 5.6 
A
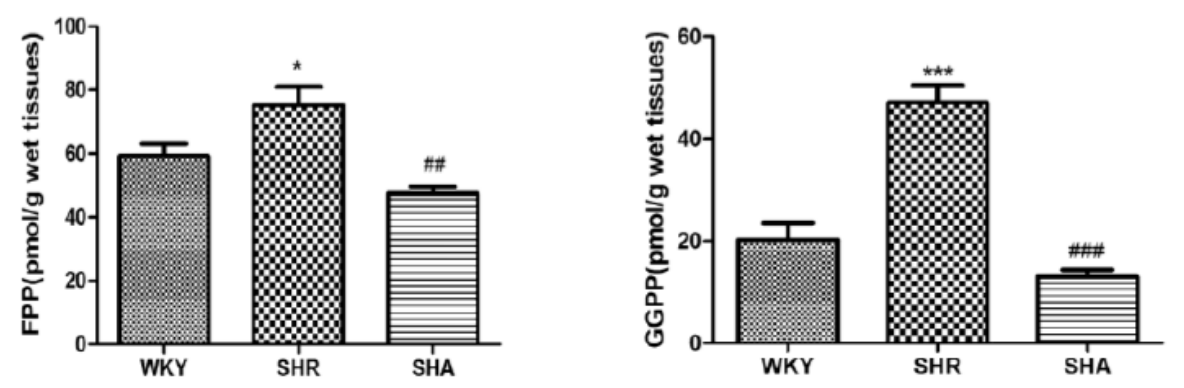

B
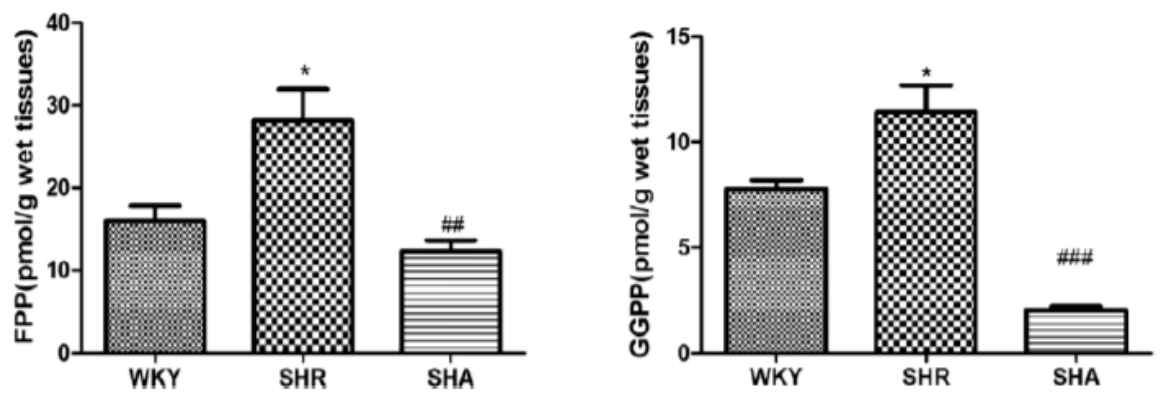

Fig. 5. FPP, GGPP concentrations in rats. (A) FPP and GGPP levels in the hearts of rats. ( $n=5 /$ group) ${ }^{*} \mathrm{p}<$ 0.05 vs. WKY, \#\# $<0.01$, \#\#\# $<0.001$ vs. SHR. (B) FPP and GGPP levels in the aortas of rats. ( $n=5 /$ group) *p $<0.05$ vs. WKY, ${ }^{\# \#} \mathrm{p}<0.01,{ }^{\# \# \#} \mathrm{p}<0.001$ vs. SHR.

vs. $59.2 \pm 3.9 \mathrm{pmol} / \mathrm{g}, \mathrm{P}<0.05 ; 47.1 \pm 3.4$ vs. $20.2 \pm 3.3 \mathrm{pmol} / \mathrm{g}, \mathrm{P}<0.001$, respectively), and the increased FPP and GGPP levels were significantly inhibited by alendronate (75.4 $\pm 5.6 \mathrm{vs.}$ $47.6 \pm 2.0 \mathrm{pmol} / \mathrm{g}, \mathrm{P}<0.01 ; 47.1 \pm 3.4$ vs. $13.0 \pm 1.4 \mathrm{pmol} / \mathrm{g}, \mathrm{P}<0.001$, respectively). FPP and GGPP levels were significantly increased in the aorta of SHR compared with WKY rats $(28.2$ \pm 3.8 vs. $16.0 \pm 1.9 \mathrm{pmol} / \mathrm{g}, \mathrm{P}<0.05 ; 11.4 \pm 1.3$ vs. $7.8 \pm 0.4 \mathrm{pmol} / \mathrm{g}, \mathrm{P}<0.05$, respectively). In addition, the increased FPP and GGPP levels were significantly inhibited by alendronate $(28.2$ \pm 3.8 vs. $12.3 \pm 1.4 \mathrm{pmol} / \mathrm{g}, \mathrm{P}<0.01 ; 11.4 \pm 1.3$ vs. $2.03 \pm 0.20 \mathrm{pmol} / \mathrm{g}, \mathrm{P}<0.001$, respectively).

Inhibition of FPPS decreases RhoA activity and geranylgeranylation in SHR

Protein prenylation including geranylgeranylation and farnesylation by FPP and GGPP is necessary for the activation of small GTPases. FPPS inhibition decreases isoprenoid intermediates that are important for the activity of small GTPases. The proportions of the geranylgeranylated forms of RhoA in rat heart and aorta were determined by the Triton X-114 partition method, which indicated that the percentages of the geranylgeranylated forms of RhoA in SHR heart and aorta were significantly increased, and significantly decreased in the SHA group (Fig. 6). Our study also showed that RhoA activity was significantly increased in the heart and aorta of SHR compared with WKY rats (Fig. 6). The FPPS inhibitor, alendronate, significantly reduced RhoA activity (Fig. 6). These results suggest that FPPS is involved in cardiac and vascular remodeling in SHR, at least in part, through RhoA activation and geranylgeranylation.

To examine the effects of alendronate on the activation status of Ras in the heart and aorta of SHR, we evaluated active Ras and farnesylated Ras, which were significantly increased in the heart and aorta of SHR compared with WKY rats, and alendronate treatment 
A

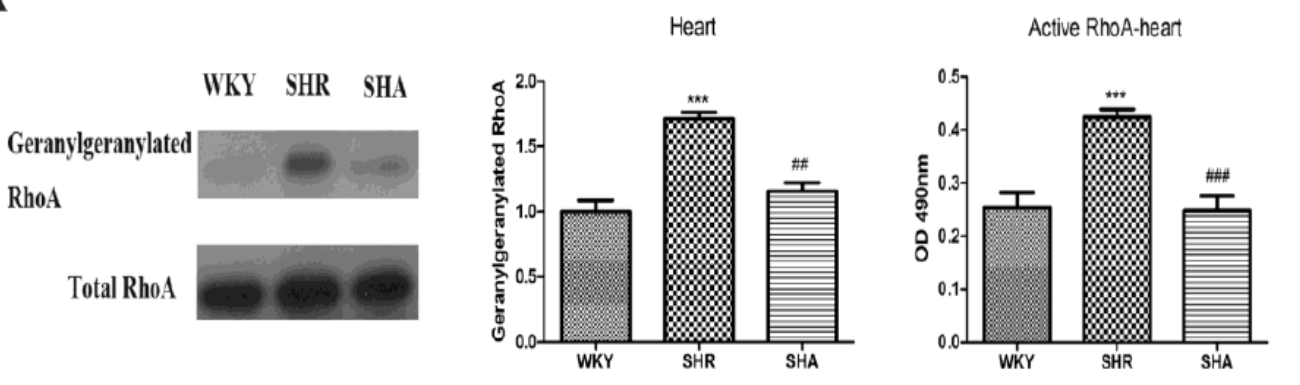

B

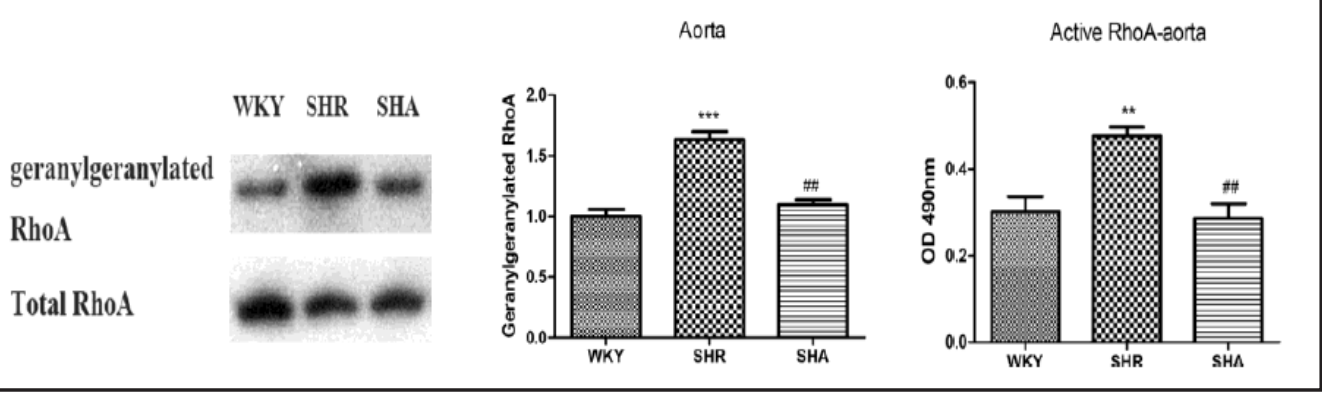

Fig. 6. RhoA activity and geranylgeranylation in rats. (A) RhoA activity and geranylgeranylation in the hearts of rats. ( $\mathrm{n}=3$ /group) ${ }^{* * *} \mathrm{p}<0.001 \mathrm{vs}$. WKY, ${ }^{\# \#} \mathrm{p}<0.01$, \#\#\# $\mathrm{p}<0.001 \mathrm{vs}$. SHR. (B) RhoA activity and geranylgeranylation in the aortas of rats. ( $\mathrm{n}=3$ /group) ${ }^{* *} \mathrm{p}<0.01,{ }^{* * *} \mathrm{p}<0.001 \mathrm{vs.}$ WKY, ${ }^{\# \#} \mathrm{p}<0.01$, vs. SHR.

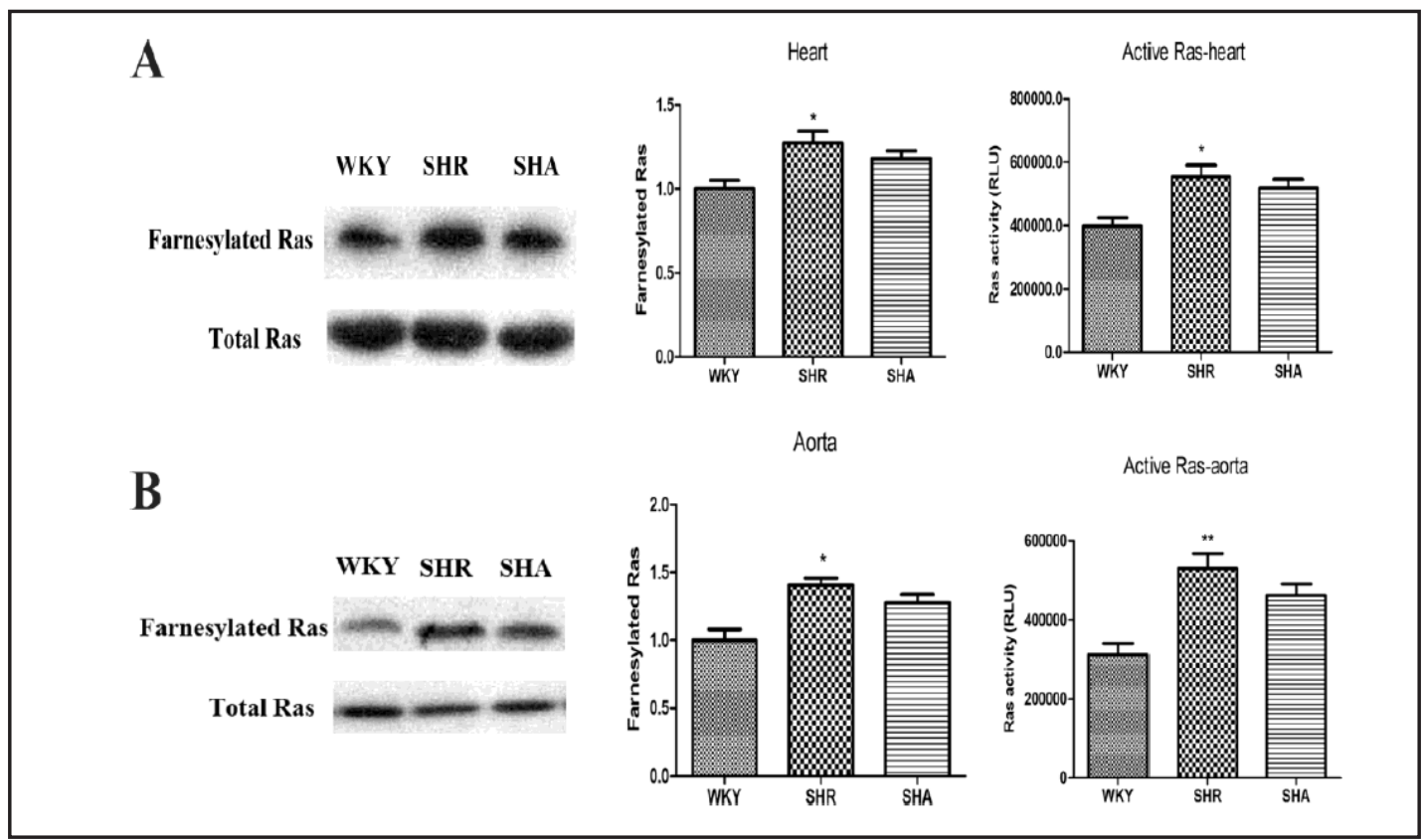

Fig. 7. Ras activity and farnesylation in rats. (A) Ras activity and farnesylation in the hearts of rats. $(n=3 /$ group) "p $<0.05 v s$. WKY. (B) Ras activity and farnesylation in the aortas of rats. (n = 3/group) ${ }^{*} p<0.05,{ }^{* *} p$ $<0.01 v s$. WKY.

could not reverse increased farnesylated and active Ras (Fig. 7). These results indicate that FPPS inhibition may not be involved in the Ras pathway in SHR. 


\section{Cellular Physiology Cell Physiol Biochem 2016;39:229-241 \\ and Biochemistry Published online: June 24, $2016 \quad \begin{aligned} & \text { DOI: 10.1159/000445619 } 2016 \text { The Author(s). Published by S. Karger AG, Basel } \\ & \text { www.karger.com/cpb }\end{aligned}$ \\ Yang et al: FPPS Inhibition and Cardiovascular Remodeling}

\section{Discussion}

In this study, we found the FPPS inhibitor alendronate attenuated cardiac hypertrophy and fibrosis as indicated by reduced HW/BW ratio, HW/TL ratio, IVSd, LVPWT and crosssectional area of cardiomyocytes. This inhibitor also decreased lipid levels and ameliorated aortic remodeling as indicated by decreased MT, MCSA, collagen of the aorta as well as reduced SBP, DBP, MBP in SHR. Furthermore, we also examined FPP and GGPP levels, the geranylgeranylated forms of RhoA and the farnesylated forms of Ras, the activity of RhoA and Ras. The results not only proved the essential role of FPPS in cardiac and vascular remodeling, but showed that the GGPP level and geranylgeranylation of RhoA may be an important part of the mevalonate metabolic pathway in modulating cardiac and vascular remodeling.

RhoA belongs to the Rho subfamily of GTP-binding proteins that regulate the actin cytoskeleton and has a wide range of effects. RhoA plays important pathophysiological roles in the cardiovascular system and in disease states such as hypertension, heart failure, stroke, diabetes and others $[22,23]$. We found that RhoA activation and geranylgeranylation of RhoA in the tissue of the heart increased at week 6 of SHR although there was no significant difference, but it significantly increased at week 12 of SHR (data not shown). What's more, RhoA activation and geranylgeranylation of RhoA in the tissue of the aorta significantly increased at week 6 of SHR (data not shown), which suggested that increased RhoA activity in SHR may be a primary event mediated by cardiac and vascular remodeling.

Approximately 300 proteins in the human proteome are prenylated by GGPP and FPP, particularly members of the Ras superfamily of small GTPases (e.g., Ras, Rab, Rho etc.).Knowing these levels is very important, as there is great interest in the role of prenylated proteins in neurodegenerative diseases and cardiovascular disease. Therefore, it is important to quantify FPP and GGPP levels. To the best of our knowledge, we have, for the first time, quantitatively determined FPP and GGPP in the heart and aorta of SHR. The results showed that FPP and GGPP levels were higher in the heart and aorta of SHR compared to WKY rats, and were significantly inhibited by alendronate, especially GGPP levels. These findings showed that FPP and GGPP may contribute to cardiac hypertrophy and fibrosis through a variety of downstream signals, such as RhoA or Ras activation. Consistent with a previous study [17], FPP and GGPP levels were significantly increased in mice with Ang-II induced cardiac hypertrophy, and were significantly inhibited by alendronate.

It is known that geranylgeranylpyrophosphate synthase (GGPPS) is a key enzyme in the utilization of FPP to form GGPP, geranylgeranylating small G proteins to promote the protein-membrane interaction and downstream signaling activation. However, the specific role of GGPPS in MVP is still under investigation. Xu et al. [24] reported that cardiac-specific GGPPS knockout mice died at approximately two months old due to severe heart failure, accompanied by GGPPS deletion in cardiomyocytes which may lead to a disruption in the balance between protein farnesylation and geranylgeranylation. The authors also indicated that if FTase was inhibited, the geranylgeranylated protein level would be significantly upregulated, such as K-Ras [25]. Therefore, they implied that both the geranylgeranylation and the farnesylation state of these proteins may play important roles in the hypertrophic response. Therefore, the equilibrium between these two types of prenylation in the heart is critical. Statins are used for the treatment of cardiac hypertrophy and fibrosis due to their anti-inflammatory effect $[26,27]$. In addition, statins can prevent the development of cardiac hypertrophy and protect the myocardium from ischemia-reperfusion injury through the inhibition of Rac1 [26] and RhoA [28] geranylgeranylation. However, statins can totally inhibit protein prenylation and sometimes exert severe side effects. There may be a reasonable explanation for statin-induced myopathies, such as the geranylgeranylation and farnesylation balance is disrupted by statin treatment. Similar to statins, FPPS inhibition can totally inhibit protein prenylation and may disrupt this balance. Therefore, it is interesting to know the protein prenylation levels before and after FPPS inhibition in SHR. In the present study, we treated SHR with alendronate, and both the FPP and GGPP level, RhoA activity and 


\section{Cellular Physiology Cell Physiol Biochem 2016;39:229-241 and Biochemistry Published online: June 24, $2016 \quad \begin{aligned} & \text { DOI: 10.1159/000445619 } 2016 \text { The Author(s). Published by S. Karger AG, Basel } \\ & \text { www.karger.com/cpb }\end{aligned}$ \\ Yang et al: FPPS Inhibition and Cardiovascular Remodeling}

the geranylgeranylated form of RhoA were significantly decreased, which indicated that GGPP and RhoA may be the downstream effectors of FPPS and the geranylgeranylation of RhoA by GGPP has an important effect on RhoA activation. It is known that GGPP and FPP-two types of isoprenoids-prenylate proteins by their addition to a cysteine residue located at or near the carboxyl terminal end of the protein [13]. Furthermore, the geranylgeranylated form of RhoA is prone to anchor proteins to intracellular membranes and triggers a downstream cell signaling pathway $[13,29,30]$, activating the RhoA/ROCK pathway which mediates a hypertropic response [31]. In this study, the geranylgeranylated form of RhoA was tested, which is the best evidence to support the hypothesis that GGPP plays an important role in cardiac hypertrophy and fibrosis by the regulation of RhoA geranylgeranylation. In another study (not published), we found that geranylgeranylation of RhoA increased in the transverse aortic constriction (TAC) mice, which also indicated that geranylgeranylation of RhoA might play an important role in modulating cardiac remodeling. On the other hand, although the farnesylated Ras and active Ras were significantly increased in the heart and aorta of SHR, there were no significant differences after FPPS inhibition. These results indicate that FPPS inhibition mainly influences protein geranylgeranylation in SHR. However, this may occur due to other reasons. Firstly, as the GGPP level was inhibited more than the FPP level after alendronate treatment, alendronate may also inhibit GGPPS activity [32-34], and decrease the synthesis of GGPP, which ultimately influences protein geranylgeranylation. Secondly, following FPPS inhibition, the prenylation of many small GTPases would also be affected due to the alteration in FPP and GGPP levels. Reversed cardiovascular remodeling might be the consequence of activity alteration of all GTPases together. Thirdly, as in a previous study [35], the GGTase-I was increased more than Ftase in the heart and aorta of SHR, and there may be a higher level of protein geranylgeranylation than protein farnesylation in SHR. Therefore, protein geranylgeranylation may be inhibited more after alendronate treatment than farnesylation in order to equilibrate protein prenylation.

In addition, we also measured SBP, DBP, MBP, lipid levels, the HW/BW ratio, HW/TL ratio, IVSd, LVPWT, cross-sectional area of cardiomyocytes, MT and MCSA of the thoracic aorta, which are basic pathological changes in cardiac hypertrophy and fibrosis, as well as the size, wall thickness and contractile function of the cardiac chamber. The results obtained were as expected.

In conclusion, we provide experimental evidence that chronic inhibition of FPPS by alendronate decreased the development of cardiovascular remodeling, probably by downregulating FPP and GGPP levels, and RhoA activation and geranylgeranylation. We further hypothesize that the function of alendronate in cardiovascular protection is associated with the RhoA geranylgeranylation and activation.

\section{Disclosure Statement}

None declared.

\section{Acknowledgments}

This work was supported by the National Natural Science Foundation of China (Project No. 81400295), the Research Fund of the Health Agency of Zhejiang Province (Nos. 2014KYB099, 2016KYB100), and the Zhejiang Provincial Natural Science Foundation of China (No.LQ14H020004).

\section{References}

1 Richardson P, McKenna W, Bristow M, Maisch B, Mautner B, O'Connell J, Olsen E, Thiene G, Goodwin J, Gyarfas I, Martin I, Nordet P: Report of the 1995 World Health Organization/International Society and Federation of Cardiology Task Force on the Definition and Classification of cardiomyopathies. Circulation 1996;93:841-842. 


\section{Cellular Physiology Cell Physiol Biochem 2016;39:229-241 and Biochemistry Published online: June 24, $2016 \quad \begin{aligned} & \text { DOI: 10.1159/000445619 } 2016 \text { The Author(s). Published by S. Karger AG, Basel } \\ & \text { www.karger.com/cpb }\end{aligned}$ \\ Yang et al: FPPS Inhibition and Cardiovascular Remodeling}

2 Chien KR: Stress pathways and heart failure. Cell 1999;98:555-558.

3 Yung CK, Halperin VL, Tomaselli GF, Winslow RL: Gene expression profiles in end-stage human idiopathic dilated cardiomyopathy: altered expression of apoptotic and cytoskeletal genes. Genomics 2004;83:281297.

4 Brown JH, Del RDP, Sussman MA: The Rac and Rho hall of fame: a decade of hypertrophic signaling hits. Circ Res 2006;98:730-742.

5 Heineke J, Molkentin JD: Regulation of cardiac hypertrophy by intracellular signalling pathways. Nat Rev Mol Cell Biol 2006;7:589-600.

$6 \quad$ Hill JA, Olson EN: Cardiac plasticity. N Engl J Med 2008;358:1370-1380.

7 Burchfield JS, Xie M, Hill JA: Pathological ventricular remodeling: mechanisms: part 1 of 2 . Circulation 2013;128:388-400.

8 Sah VP, Minamisawa S, Tam SP, Wu TH, Dorn GW 2nd, Ross J Jr, Chien KR, Brown JH: Cardiac-specific overexpression of RhoA results in sinus and atrioventricular nodal dysfunction and contractile failure. J Clin Invest 1999;103:1627-1634.

9 Lauriol J, Keith K, Jaffre F, Couvillon A, Saci A, Goonasekera SA, McCarthy JR, Kessinger CW, Wang J, Ke Q Kang PM, Molkentin JD, Carpenter C, Kontaridis MI: RhoA signaling in cardiomyocytes protects against stress-induced heart failure but facilitates cardiac fibrosis. Sci Signal 2014;7:ra100.

10 Sussman MA, Welch S, Walker A, Klevitsky R, Hewett TE, Price RL, Schaefer E, Yager K: Altered focal adhesion regulation correlates with cardiomyopathy in mice expressing constitutively active rac1. J Clin Invest 2000;105:875-886.

11 Hunter JJ, Tanaka N, Rockman HA, Ross J Jr, Chien KR: Ventricular expression of a MLC-2v-ras fusion gene induces cardiac hypertrophy and selective diastolic dysfunction in transgenic mice. J Biol Chem 1995;270:23173-178.

12 Casey PJ: Protein lipidation in cell signaling. Science 1995;268:221-225.

13 Perez-Sala D: Protein isoprenylation in biology and disease: general overview and perspectives from studies with genetically engineered animals. Front Biosci 2007;12:4456-4472.

14 Konstantinopoulos PA, Karamouzis MV, Papavassiliou AG: Post-translational modifications and regulation of the RAS superfamily of GTPases as anticancer targets. Nat Rev Drug Discov 2007;6:541-555.

15 Li L, Chen GP, Yang Y, Ye Y, Yao L, Hu SJ: Chronic inhibition of farnesyl pyrophosphate synthase attenuates cardiac hypertrophy and fibrosis in spontaneously hypertensive rats. Biochem Pharmacol 2010;79:399406.

16 Yang J, Mou Y, Wu T, Ye Y, Jiang JC, Zhao CZ, Zhu HH, Du CQ, Zhou L, Hu SJ: Cardiac-specific overexpression of farnesyl pyrophosphate synthase induces cardiac hypertrophy and dysfunction in mice. Cardiovasc Res 2013;97:490-499.

17 Yang J, Zhu HH, Chen GP, Ye Y, Zhao CZ, Mou Y, Hu SJ: Inhibition of farnesyl pyrophosphate synthase attenuates angiotensin II-induced cardiac hypertrophy and fibrosis in vivo. Int J Biochem Cell Biol 2013;45:657-666.

18 Stabnov L, Kasukawa Y, Guo R, Amaar Y, Wergedal JE, Baylink DJ, Mohan S: Effect of insulin-like growth factor-1 (IGF-1) plus alendronate on bone density during puberty in IGF-1-deficient MIDI mice. Bone 2002;30:909-916.

19 Nakamura Y, Naito M, Hayashi K, Fotovati A, Abu-Ali S: Effect of combined treatment with alendronate and calcitriol on femoral neck strength in osteopenic rats. J Orthop Surg Res 2008;3:51.

20 Draznin B, Miles P, Kruszynska Y, Olefsky J, Friedman J, Golovchenko I, Stjernholm R, Wall K, Reitman M, Accili D, Cooksey R, McClain D, Goalstone M: Effects of insulin on prenylation as a mechanism of potentially detrimental influence of hyperinsulinemia. Endocrinology 2000;141:1310-1316.

21 Tong H, Wiemer AJ, Neighbors JD, Hohl RJ: Quantitative determination of farnesyl and geranylgeranyl diphosphate levels in mammalian tissue. Anal Biochem 2008;378:138-143.

22 Lu XC, Zheng JY, Tang LJ, Huang BS, Li K, Tao Y, Yu W, Zhu RL, Li S, Li LX: MiR-133b Promotes neurite outgrowth by targeting RhoA expression. Cell Physiol Biochem 2015;35:246-258.

23 Liu D, Xiong R, Chen X, Li P, Ning Y, Peng Y, Zhao Y, Yang N, Zhou Y: The glucocorticoid dexamethasone inhibits U937 cell adhesion and neutrophil release via RhoA/ROCK1-dependent and independent pathways.Cell Physiol Biochem 2014;33:1654-1662. 


\section{Cellular Physiology Cell Physiol Biochem 2016;39:229-241 \begin{tabular}{l|l} 
DOI: 10.1159/000445619 & $\begin{array}{l}\text { O 2016 The Author(s). Published by S. Karger AG, Basel } \\
\text { www.karger.com/cpb }\end{array}$
\end{tabular} \\ Yang et al: FPPS Inhibition and Cardiovascular Remodeling}

24 Xu N, Guan S, Chen Z, Yu Y, Xie J, Pan FY, Zhao NW, Liu L, Yang ZZ, Gao X, Xu B, Li CJ: The alteration of protein prenylation induces cardiomyocyte hypertrophy through Rheb-mTORC1 signalling and leads to chronic heart failure. J Pathol 2015;235:672-685.

25 Whyte DB, Kirschmeier P, Hockenberry TN, Nunez-Oliva I, James L, Catino JJ, Bishop WR, Pai JK: K- and $\mathrm{N}$-Ras are geranylgeranylated in cells treated with farnesyl protein transferase inhibitors. J Biol Chem 1997;272:14459-14464.

26 Takemoto M, Node K, Nakagami H, Liao Y, Grimm M, Takemoto Y, Kitakaze M, Liao JK: Statins as antioxidant therapy for preventing cardiac myocyte hypertrophy. J Clin Invest 2001;108:1429-1437.

27 Liao JK: Statin therapy for cardiac hypertrophy and heart failure. J Investig Med 2004;52:248-253.

28 Bulhak A, Roy J, Hedin U, Sjoquist PO, Pernow J: Cardioprotective effect of rosuvastatin in vivo is dependent on inhibition of geranylgeranyl pyrophosphate and altered RhoA membrane translocation. Am J Physiol Heart Circ Physiol 2007;292:H3158-163.

29 Takai Y, Sasaki T, Matozaki T: Small GTP-binding proteins. Physiol Rev 2001;81:153-208.

30 Xu N, Shen N, Wang X, Jiang S, Xue B, Li C: Protein prenylation and human diseases: a balance of protein farnesylation and geranylgeranylation. Sci China Life Sci 2015;58:328-335.

31 Miyamoto S, Del RDP, Xiang SY, Zhao X, Florholmen G, Brown JH: Revisited and revised: is RhoA always a villain in cardiac pathophysiology. J Cardiovasc Transl Res 2010;3:330-343.

32 Szabo CM, Matsumura Y, Fukura S, Martin MB, Sanders JM, Sengupta S, Cieslak JA, Loftus TC, Lea CR, Lee HJ, Koohang A, Coates RM, Sagami H, Oldfield E: Inhibition of geranylgeranyl diphosphate synthase by bisphosphonates and diphosphates: a potential route to new bone antiresorption and antiparasitic agents. J Med Chem 2002;45:2185-2196.

33 Guo RT, Cao R, Liang PH, Ko TP, Chang TH, Hudock MP, Jeng WY, Chen CK, Zhang Y, Song Y, Kuo CJ, Yin F, Oldfield E, Wang AH: Bisphosphonates target multiple sites in both cis- and trans-prenyltransferases. Proc Natl Acad Sci U S A 2007;104:10022-10027.

34 K-M CC, Hudock MP, Zhang Y, Guo RT, Cao R, No JH, Liang PH, Ko TP, Chang TH, Chang SC, Song Y, Axelson J, Kumar A, Wang AH, Oldfield E: Inhibition of geranylgeranyl diphosphate synthase by bisphosphonates: a crystallographic and computational investigation. J Med Chem 2008;51:5594-5607.

35 Han J, Jiang DM, Du CQ, Hu SJ: Alteration of enzyme expressions in mevalonate pathway: possible role for cardiovascular remodeling in spontaneously hypertensive rats. Circ J 2011;75:1409-1417. 